K

линические особенности мастоцитоза у пациентов детского возраста

\author{
Д. В. Прошутинская, О. С. Маковецкая
}

ФГБУ «Государственный научный центр дерматовенерологии и косметологии» Минздрава России 107076, г. Москва, ул. Короленко, д. 3, стр. 6

Мастоцитоз относится к гетерогенной группе заболеваний, обусловленных чрезмерным накоплением

и пролисрерацией в тканях тучных клеток. У детей встречается преимущественно кожная форма мастоцитоза.

В статье приведены современные данные об этиологии, патогенезе, классифиикации, клинических формах,

диагностике, просрилактике и лечении мастоцитоза у детей.

Ключевые слова: мастоцитоз, тучные клетки, генотип, с-KIT, мутации.

Контактная информация: diana.dika@mail.ru. Вестник дерматологии и венерологии 2017; (1): 12_20.

\title{
Clinical features of mastocytosis at pediatric patients
}

D. V. Proshutinskaya, 0. S. Makoveckaya

State Research Center of Dermatovenereologyand Cosmetology, Ministry of Healthcare of the Russian Federation Korolenko str., 3, bldg 6, Moscow, 107076, Russia

Mastocytosis is relevant to heterogeneous disease group characterized with redundant accumulation and proliferation of mast cells in tissues. The skin form of mastocytosis is mainly occurs in children. The article contains the current data on etiology, pathogenesis, classification, clinical forms, diagnosis, prophylactics and mastocytosis treatment at children.

Key words: mastocytosis, mast cells, genotype, c-KIT, mutations

Corresponding author: diana.dika@mail.ru. Vestnik Dermatologii i Venerologii 2017; 1: 12—20. 
Мастоцитоз представляет собой гетерогенную группу заболеваний, характеризующихся патологической локальной или диффрузной пролиферацией и накоплением тучных клеток (мастоцитов) в коже и/или других органах (костном мозге, печени, селезенке, лимфатических узлах) [1-4].

В 1869 г. Nettleship и Тау описали клиническую картину поражения кожи при мастоцитозе как разновидность хронической крапивницы, регрессирующую с фрормированием стойких коричневых пятен. Это послужило введению термина «пигментная крапивница» для обозначения кожных высыпаний при мастоцитозе [5]. Более четко природа заболевания была определена в 1887 г. P. Unna в результате гистологических исследований, термин «мастоцитоз» был предложен Sezarg в 1936 г., а широко внедрен в практику R. Degos в 1953 г. [6, 7].

Точная распространенность мастоцитоза неизвестна. По данным различных эпидемиологических исследований, она варьирует от 1 на 1000 до 1 на 8000 [8]. Ежегодно отмечается 5-10 новых случаев на 1000000 в популяции [9]. Частота возникновения мастоцитоза не зависит от пола и расовой принадлежности и одинаково встречается как у лиц мужского, так и женского пола [10]. Заболевание чаще возникает спорадически без генетической предрасположенности. Наследственный мастоцитоз - достаточно редкое явление. Однако описано около 50 семейных случаев заболевания [11, 12]. Заболевание может впервые возникнуть в любом возрасте. В $65 \%$ случаев клинические проявления мастоцитоза отмечаются в детском возрасте [13]. По данным I. Silva и соавт., частота встречаемости мастоцитоза у детей соответствует $5,4 \%$, при этом в половине случаев дебют отмечается в период до 2 лет [14-16]. С рождения заболевание наблюдается у $15 \%$ больных, в возрасте до 6 мес. - у 30\%, до 2 лет - у 10\%, от 2 до 15 лет у $10 \%$ пациентов [17].

Y. Shiloh Malawsky и соавт. (2003) отмечали только кожную форму мастоцитоза у $90 \%$ детей, тогда как у $10 \%$ имелось сочетанное поражение кожи и других органов и систем [18].

У взрослых дебют заболевания чаще всего приходится на возраст от 20 до 36 лет, но описаны случаи возникновения и в более позднем возрасте - 6570 лет [6, 19].

\section{Патогенез}

Этиология до конца не известна. Характерным морфологическим признаком мастоцитоза является пролиферация и накопление в тканях клеток мастоцитов. Мастоциты (или тучные клетки) развиваются из плюрипотентных гемопоэтических стволовых клеток. Покидая костный мозг, мастоциты мигрируют в кровь и ткани, где пролиферируют и диффреренцируются в зрелые клетки, экспрессирующие CD117 [20-22].
CD117 (kit-протеин) - трансмембранный рецептор тирозинкиназа, который, связываясь с фактором стволовых клеток (SCF, kit-лиганд), в норме обеспечивает передачу внутриклеточных сигналов, необходимых для пролиферации и дифференцировки клеток [23]. Взаимодействие kit-протеина и kit-лиганда контролируется протоонкогеном с-KIT [24-26].

Многообразие клинических проявлений мастоцитоза предполагает возможное участие различных звеньев в патогенезе этого заболевания. Так, изучались роль повышенной экспрессии фрактора стволовых клеток кератиноцитами и/или изменение его рецептора, изменение уровня сывороточного фактора роста нервов, хромосомных аномалий, нарушений регуляции апоптоза [9, 27-29]. Однако ведущую роль в патогенезе различных клинических форм мастоцитоза отводят точечным мутациям протоонкогена с-KIT в хромосоме 4q12, кодирующим активность взаимодействия kit-лиганда и kit-протеина [30-32].

В результате научных исследований определены некоторые мутации гена с-KIT, встречающиеся при различных формах мастоцитоза [30] (табл. 1).

Наличие этих мутаций обусловливает бесконтрольную пролифрерацию и трансформацию мастоцитов, накопление в них тирозинкиназы (CD117), дегрануляцию с высвобождением гистамина, гепарина, фермента триптазы, лейкотриенов и простагландинов, содержащихся в гранулах тучных клеток [33-35], что влечет за собой появление характерных высыпаний на коже и зуда. В настоящее время наиболее изученной при мастоцитозе является мутация гена C-KIT D816V [36]. По данным K. Hartmann, мутация гена C-KIT D816V присутствует в экзоне 17 у 80\% взрослых пациентов, по данным C. Bodemer, она обнаруживается в экзонах $8,9,11$ у $40 \%$ детей $[15,37]$.

F. Lanternier и соавт. (2008) было проведено исследование с участием 142 пациентов с гистологически подтвержденным диагнозом кожного или системного мастоцитоза [6]. Среди них у 28 больных заболевание развилось в детском возрасте (1-я группа), у 114 больных дебют заболевания относился ко взрослому возрасту (2-я группа). При обследовании пациентов мутация гена c-KIT D816V в экзонах 8, 13 и 17 была обнаружена у 42 и 77\% больных 1-й и 2-й групп соответственно $(p=0,001)$. При этом мутация c-KIT D816V во 2-й группе была чаще ассоциирована с системным мастоцитозом, чем с кожной фрормой $(p=0,0001)$. Другие мутации c-KIT обнаруживались при дебюте заболевания в возрасте до 5 лет у $23 \%$ больных, в возрасте 6-15 лет - у 0\% больных, во взрослом возрасте у $2 \%$ больных $(p=0,001)$, что не противоречит данным C. Bodemer (2010), обнаружившей у $25 \%$ пациентов детского возраста неидентифицированные мутации дикого типа. Полученные результаты позволили предположить авторам, что превалирование тех или иных генетических мутаций обусловливает различия 
Таблица 1 Мутации гена с-KIT, выявленные у больных с разными формами мастоцитоза

(адаптировано из А. Orfao и соавт., 2007 [30])

\begin{tabular}{lcl}
\hline \multicolumn{1}{c}{ Экзон } & Мутация & \multicolumn{1}{c}{ Форма мастоцитоза } \\
\hline 8 & delD419 & Семейный системный мастоцитоз (Hartmann K., 2005) \\
\hline 9 & K509I & Семейный системный мастоцитоз (Zhang L.Y., 2006) \\
\hline 10 & A533D & Семейный системный мастоцитоз (Tang X., 2004) \\
\hline 11 & V559I & Агрессивный системный мастоцитоз (Nakagomi N., Hirota S., 2007) \\
\hline 11 & V560G & Индолентный системный мастоцитоз, лейкемия тучных клеток (Furitsu T. и coaвт., 1993; Buttner C., 1998) \\
\hline 17 & R815K & Детский пятнисто-папулезный мастоцитоз (Sotlar K. и соавт., 2003) \\
\hline 17 & D816V & Детский пятнисто-папулезный мастоцитоз (Yanagihori H., 2005) \\
\hline 17 & Системный мастоцитоз (Longley B. и соавт., 1999) \\
\hline 17 & D816H & Системный мастоцитоз - острая миелобластная лейкемия (Pullarkat V., 2003) \\
\hline 17 & D816F & Системный мастоцитоз (Longley B. и соавт., 1999) [51] \\
\hline 17 & I817V & Системный мастоцитоз (Garcia-Montero A.C., 2006) \\
\hline 17 & D8V20G & Агрессивный системный мастоцитоз (Pignon J.M., 1997) \\
\hline
\end{tabular}

в клинической картине и течении мастоцитоза у детей и взрослых [37].

В детском возрасте мастоцитоз в большинстве случаев ограничивается только поражением кожи. Системные проявления отмечены менее чем у $20 \%$ больных детей, в то время как у взрослых пациентов системная форма развивается значительно чаще [38, 39]. Для детей, в отличие от взрослых, более характерен транзиторный характер заболевания и, по данным ряда авторов, возможен регресс высыпаний к пубертатному периоду [1, 17, 40-42]. Для взрослых, напротив, характерно хроническое течение заболевания [43].

\section{Классификация}

Современная классификации мастоцитоза включает в себя [44]:

1) кожный мастоцитоз;

2) вялотекущий (индолентный) системный мастоцитоз;

3) системный мастоцитоз, ассоциированный с гематологическим заболеванием, но не связанный с тучными клетками;

4) агрессивный системный мастоцитоз;

5) лейкемию тучных клеток.

У детей наблюдается преимущественно кожный мастоцитоз, в котором выделяют [45]:

1) мастоцитому;

2) пятнисто-папулезный кожный мастоцитоз:

мономорфный тип;

полиморфный тип;

3) диффузный кожный мастоцитоз.

\section{Клиническая картина}

Мастоцитома отмечается у 10-30\% больных. Представляет собой один или в ряде случаев несколько (до 5) очагов розовато-желтого или коричневого цвета размером от 1 до 5 см (описан до 15 см), возвышающихся над уровнем кожи, с характерной поверхностью по типу «апельсиновой кожуры», нередко с образованием на поверхности пузыря (рис. 1). Как

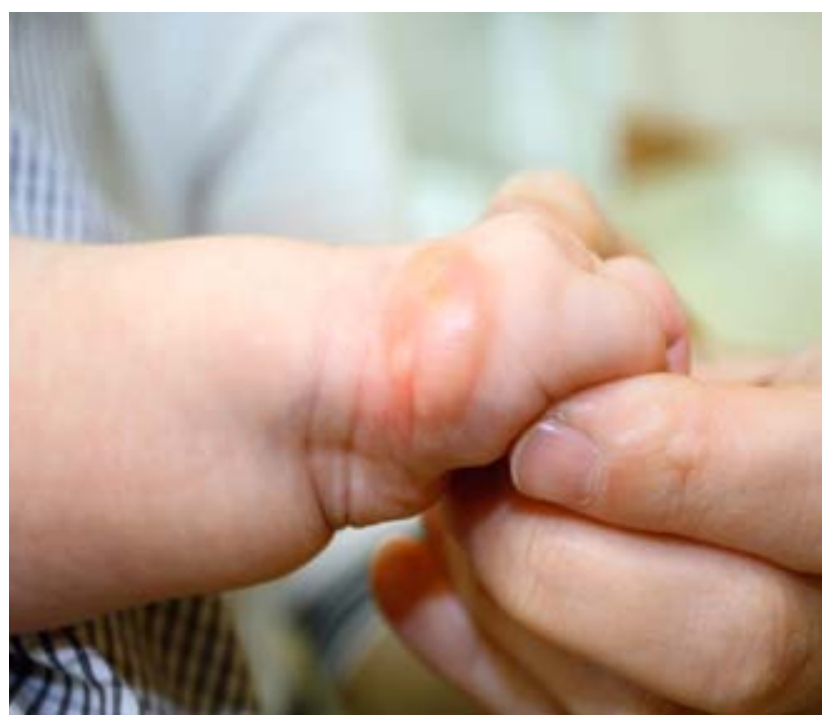

Рис. 1. Мастоцитома у ребенка в области лучезапястного сустава 
правило, у пациентов отмечается нормальный уровень сывороточной триптазы. В большинстве случаев регресс высыпаний наблюдается до пубертатного периода. Осложнения практически не отмечаются [15].

Пятнисто-папулезная форма (пигментная крапивница) - самая распространенная форма кожного мастоцитоза, отмечающаяся у 70-90\% больных в детском возрасте $[17,45]$. Очаги могут существовать с рождения или появляются в первый год жизни, быстро увеличиваясь в количестве. Высыпания представлены слегка возвышающимися красноватокоричневыми или желтоватыми пятнами, папулами или узлами. Излюбленная локализация высыпаний на туловище. В связи с выраженным клиническим разнообразием элементов в настоящее время выделяют полиморфный и мономорфный типы пятнисто-папулезного мастоцитоза.

Полиморфный тип пятнисто-папулезного кожного мастоцитоза характеризуется появлением красновато-коричневых узлов и/или бляшек, имеющих тенденцию к уменьшению в размерах и трансформации в пятна и/или папулы с возрастом ребенка (рис. 2). У больных может отмечаться повышенный уровень сывороточной триптазы в первые годы жизни, со временем приходящий к нормальным показателям. Отмечаются уменьшение интенсивности высыпаний с возрастом и склонность к регрессу высыпаний. Как правило, не сопровождается системными нарушениями [45].

Мономорфный тип пятнисто-папулезного кожного мастоцитоза характерен для взрослых и встречается у детей значительно реже [29, 30] (рис 3). Характери- зуется появлением более мелких, преимущественно пятнисто-папулезных мономорфных элементов округлых или овальных очертаний. Может сопровождаться длительно существующим повышенным уровнем сывороточной триптазы, склонностью к хроническому течению и системности процесса [45].

Дифффузный кожный мастоцитоз представляет собой крайне редкую форму кожного мастоцитоза. Характеризуется обычно не изолированными очагами, а генерализованной эритемой с желтовато-оранжевым оттенком, в пределах которой кожа утолщена по типу пахидермии. Сначала заболевание может сопровождаться образованием больших пузырей. Тенденция к уменьшению фрормирования пузырных элементов отмечается в течение первых 3-4 лет жизни. Уровень сывороточной триптазы обычно повышен. У пациентов с диффрузным кожным мастоцитозом, имеющих отягощенный наследственный анамнез, отмечается склонность к хроническому течению заболевания, повышенный уровень сывороточной триптазы, вовлечение в патологический процесс других органов [15].

K. Hartmann и соавт. (2016) были систематизированы клинические различия мастоцитоза у детей и взрослых (табл. 2) [45].

Несмотря на то что системный мастоцитоз у детей отмечается лишь в 15\% случаев по сравнению с 6090\% у взрослых, некоторые клинические особенности кожных форм позволяют предположить развитие системного поражения в будущем. К прогностически неблагоприятным относятся мономорфный тип пятнисто-папулезного кожного мастоцитоза, длительное

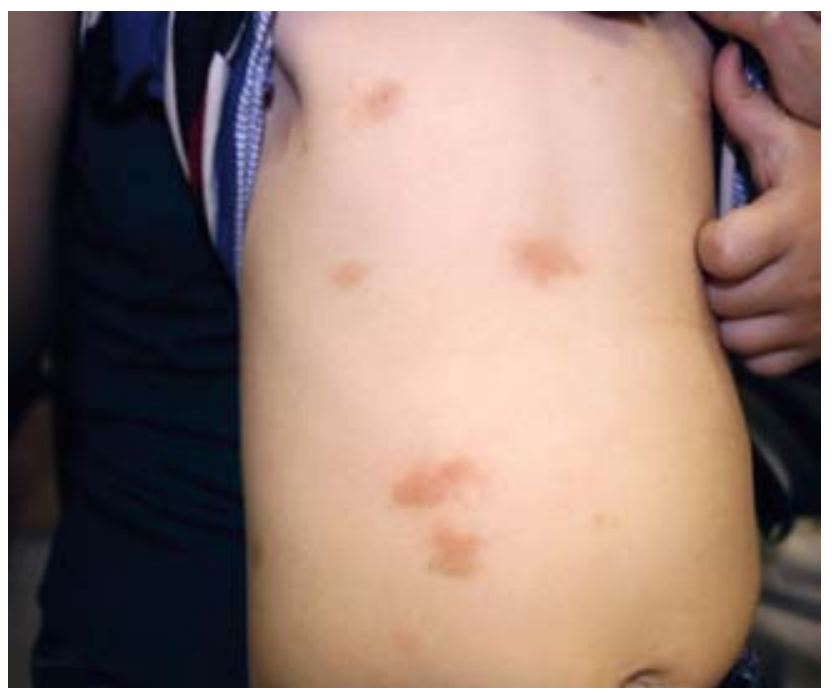

$a$

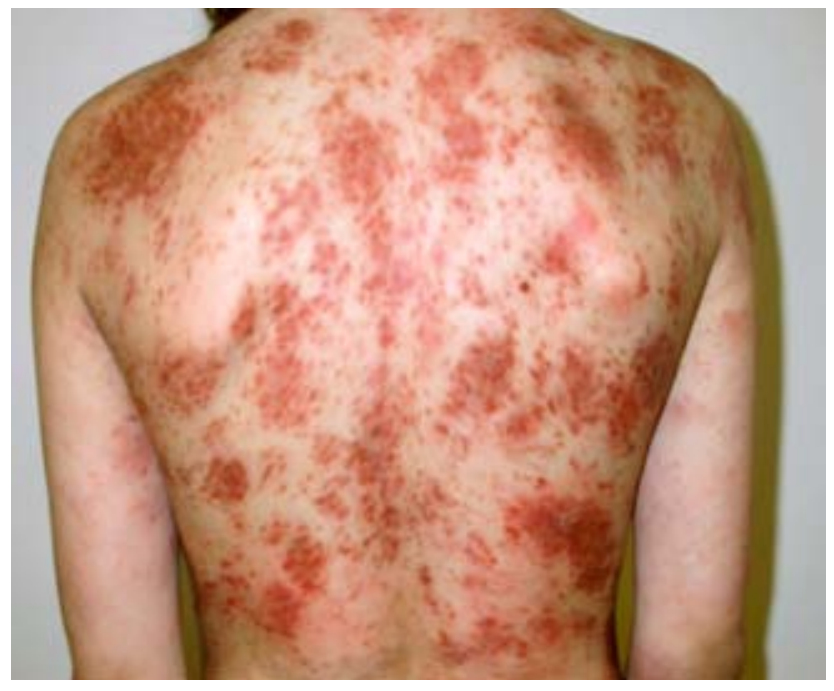

$\sigma$

Рис. 2. Различные варианты полиморфного типа пятнисто-папулезного мастоцитоза у ребенка: а — высыпания по типу бляшек, б — пятнистые высыпания 


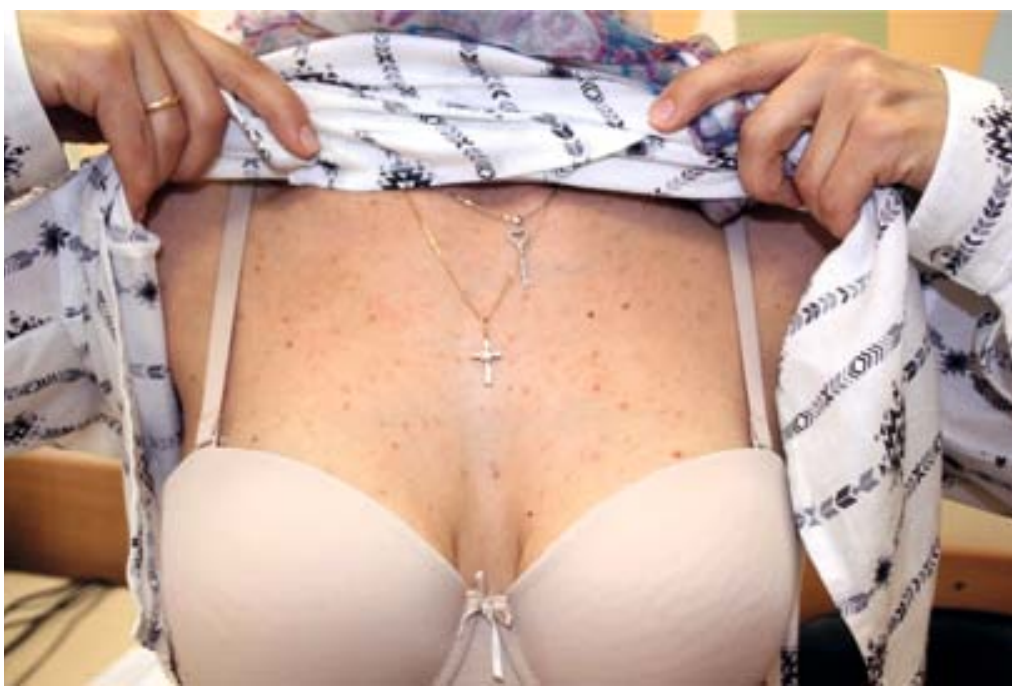

a

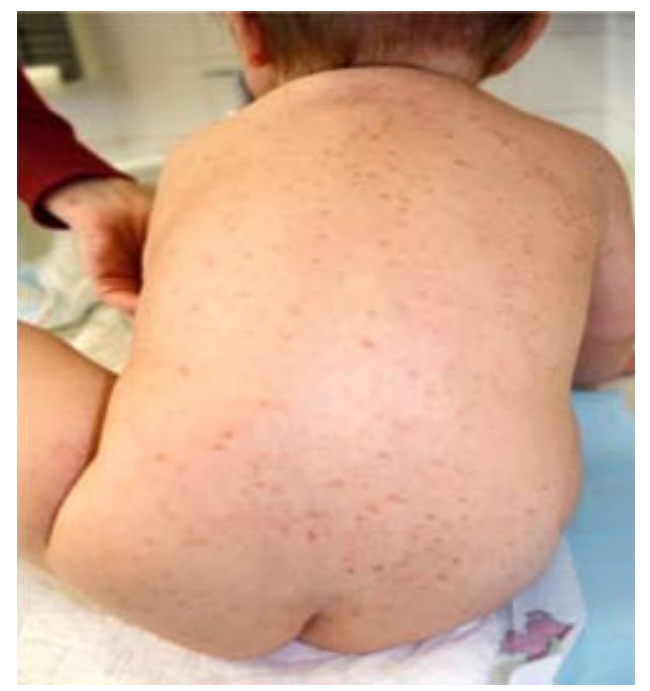

$\sigma$

Рис. 3. Мономорфный тип пятнисто-папулезного мастоцитоза у взрослого (а) и у ребенка (б)

Таблица 2 Сравнительная характеристика типичных признаков взрослого и детского мастоцитоза (адаптировано из Hartmann К. и соавт., 2013 [45])

\begin{tabular}{lcc}
\hline \multicolumn{1}{c}{ Признак } & Взрослые & Дети \\
\hline Наиболее частая клиническая форма & Системный мастоцитоз & Кожный мастоцитоз \\
\hline Течение болезни & Преимущественно хроническое & Нередко имеет транзиторный характер \\
\hline Частота анасрилаксии, \% & 50 & $<10$ \\
\hline Уровень триптазы, мг/л & $>20$ & $<20$ \\
\hline Типичное расположение мутации гена с-КIT & Экзон 17, наиболее часто с-КIT D816V & Экзон 8, 9,10, 11, 17 или отсутствует \\
\hline Типичный характер высыпаний & Мономорфрные пятна, папулы & Полифрормные пятна, папулы \\
\hline Размер поражений & Малый & Большой \\
\hline Преимущественная локализация поражений & Туловище, нижние конечности & Лицо, туловище, конечности
\end{tabular}

существование высыпаний по типу узлов, дифрузный кожный мастоцитоз [48, 49].

Клиническая картина системного мастоцитоза обусловлена инфильтрацией тучными клетками органов и тканей, поражением как минимум двух органов с их увеличением и/или нарушением функции (гепатомегалия, спленомегалия, лимфопролиферативный синдром). При этом кожа может и не быть вовлечена в патологический процесс. Повышенная функциональная активность мастоцитов с высвобождением биологически активных веществ (гистамина, гепарина, триптазы) обусловливает интоксикацию, лихорадку, снижение массы тела, приливы, профузный пот, на- рушение функции сердечно-сосудистой (тахикардия, геморрагический синдром), пищеварительной (диарея и язвенные поражения) и костной систем (остеопороз, остеофиброз) [15, 39, 44, 50].

По данным литературы, наличие мутации гена c-KIT D816V относится к фракторам риска развития тяжелых персистирующих форм кожного мастоцитоза, а также системной фрормы заболевания [51-53]. Мутация характеризуется заменой аминокислоты аспарагин на аминокислоту валин в кодоне 816. В работе Y. Hirokatsu и соавт. (2005) у 14 из 16 пациентов, больных различными формами кожного мастоцитоза, были найдены мутации c-kit в кодоне 816 [54]. Среди 
всех больных детей было 12, взрослых - 4. При этом обнаруживалась либо мутация D816V (Asp816Val), либо мутация Asp816Phe, характеризующаяся заменой аминокислоты аспарагин на аминокислоту френилаланин. Несмотря на то что D816V определялась у 70\% больных с развитием заболевания в детском возрасте, для пациентов с дебютом в более раннем возрасте в большей степени была характерна Asp816Phe. Также авторами было отмечено, что все пациенты с диффруным кожным мастоцитозом имели мутацию D816V.

Исследованиями K. Sotlar и соавт. (2003) подтверждается частое присутствие мутации D816V у детей, больных пятнисто-папулезной формой кожного мастоцитоза [38]. Однако их результаты не свидетельствуют о доминировании ее у больных с персистирующим течением пятнисто-папулезной фоормы мастоцитоза, поскольку мутация определялась у 36,4\% пациентов с хронической формой заболевания и у 44,4\% больных с транзиторной. Одновременно у 5 из 10 больных с персистирующим пятнисто-папулезным мастоцитозом отмечались так называемые дикие мутации, что согласуется с более поздними данными С. Bodemer (2010) [37, 39].

\section{Диагностические критерии}

В большинстве случаев диагноз мастоцитоза устанавливается клинически. Европейской рабочей группой по мастоцитозу в 2016 г. были определены следующие диагностические критерии заболевания [9].

\section{Большие критерии:}

- характерная клиническая картина высыпаний;

положительный симптом Дарье - Унны (механическое воздействие вызывает уртикароподобные изменения кожных высыпаний). Данный симптом обусловлен высвобождением из гранул тучных клеток большого количества гистамина, гепарина, и, как следствие, происходит расширение сосудов и повышение проницаемости их стенок [59].

\section{Малые критерии:}

п гистологическое исследование кожи;

- ДНК-диагностика мутаций гена с-КІТ в коже.

Dirk Van Gysel и соавт. (2016) был разработан диагностический алгоритм кожного мастоцитоза (см. схему) и алгоритм интерпретации уровня сывороточной триптазы (табл. 3) [15].

Для установления диагноза системных форм заболевания также был предложен ряд критериев. Так, P. Valent и соавт. [56] определили, что для установления диагноза системного мастоцитоза необходимо наличие одного главного критерия - типичных клинических проявлений и одного или двух из следующих дополнительных критериев.

Основные: мультифрокальные плотные инфильтраты мастоцитов в биоптате костного мозга и/или другого органа(ов) с иммуногистохимическим исследованием.

\section{Второстепенные:}

1) более $25 \%$ инфильтратов мастоцитов в участках костного мозга или других органах или наличие более

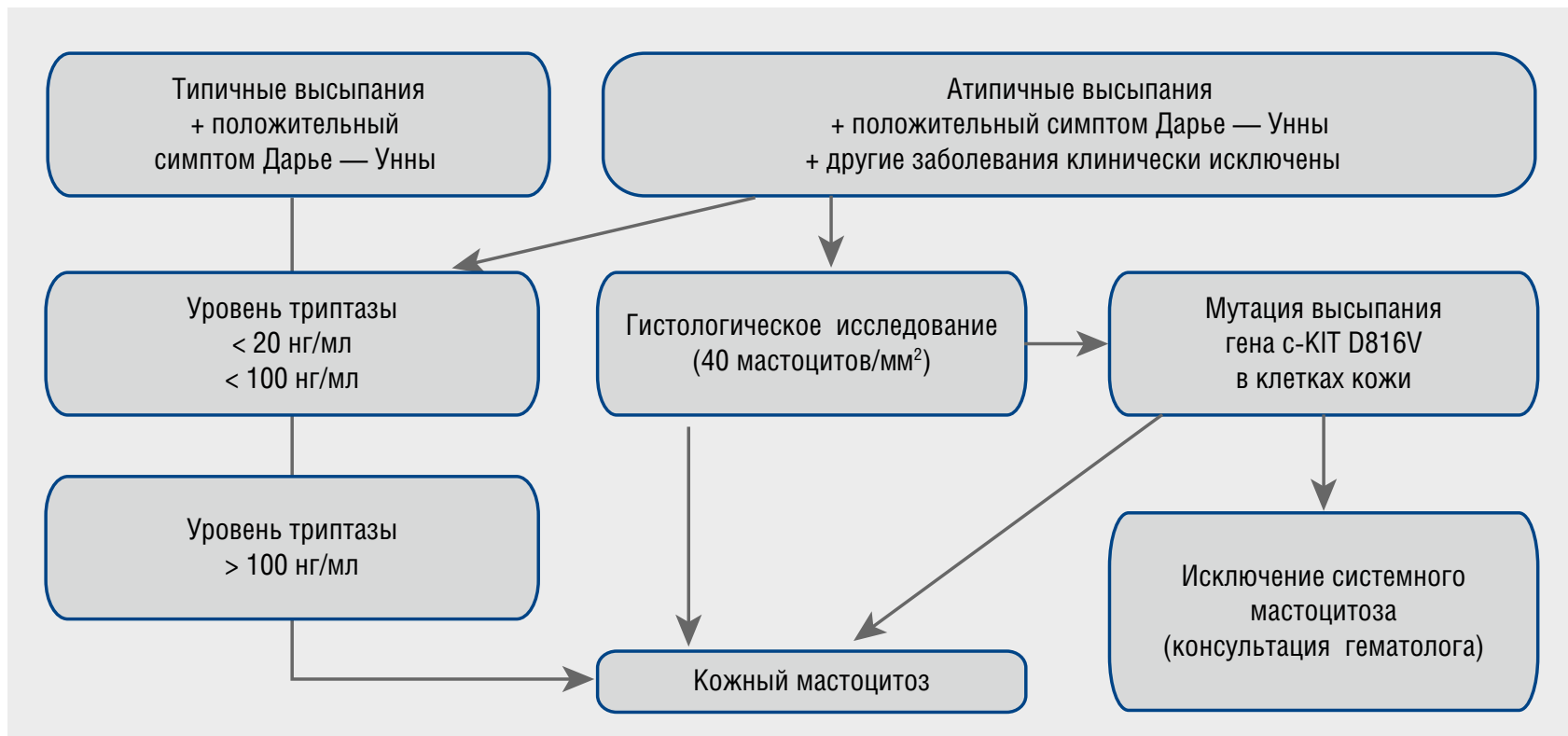

Схема Диагностический алгоритм мастоцитоза (адаптировано из Dirk Van Gysel и соавт., 2016 [15]) 
Таблица 3 Интерпретация значений сывороточной триптазы у больных мастоцитозом (адаптировано из Dirk Van Gysel и соавт., 2016 [15])

\begin{tabular}{lr}
\hline \multicolumn{1}{c}{ Уровень триптазы } & Диагноз \\
\hline$<20$ нг/мл, нет клинических проявлений системности & Кожный мастоцитоз \\
\hline $20-100$ нг/мл, нет клинических проявлений системности & Кожный мастоцитоз, мониторинг до периода пубертата \\
\hline$>20$ нг/мл, нет регресса высыпаний в постпубертате & Подозрение на системный мастоцитоз, исследование костного мозга \\
\hline$>100$ нг/мл, клинические проявления системности, нет регресса высыпаний & Исследование костного мозга \\
\hline
\end{tabular}

25\% атипичных инфильтратов мастоцитов в клетках костного мозга;

2) обнаружение точечной мутации с-KIT в кодоне 816 в костном мозге или крови или биоптате органа(ов);

3) ген с-KIT + тучные клетки в костном мозге или крови или органе совместно с экспрессией CD117, CD2, CD25;

4) концентрация триптазы сыворотки крови более 20 нг/мл [56].

\section{Лечение}

Лечение мастоцитоза в первую очередь направлено на уменьшение клинических симптомов заболевания. При этом выбор терапии зависит от фрормы заболевания. При кожной форме мастоцитоза немаловажным мероприятием является профилактика воздействия фракторов, провоцирующих дегрануляцию тучных клеток (механических, пищевых, медикаментозных) [57]. Купирование клинических проявлений осуществляется при помощи блокаторов $\mathrm{H}_{1}-$ и $\mathrm{H}_{2}$ гистаминовых рецепторов, стабилизаторов мембран тучных клеток, антилейкотриеновых препаратов, топических и системных кортикостероидных средств $[58,59]$. Имеются сведения об успешном использовании УФ-излучения спектра А в терапии мастоцитоза у взрослых пациентов [60].

При системном мастоцитозе и в отдельных случаях кожном мастоцитозе описано использование биологических препаратов [61, 62]. К последним относятся
Омализумаб, Иматиниб. Омализумаб селективно ингибирует связывание IgE с высокоаффинными рецепторами $\lg \mathrm{E}(\mathrm{Fc} \varepsilon \mathrm{Rl})$, расположенными на поверхности тучных клеток и базофилов. Иматиниб является ингибитором тирозинкиназы.

Таким образом, мастоцитоз характеризуется не только многообразием клинических форм, но и вероятной гетерогенностью молекулярно-генетических дефектов у больных, особенно в детском возрасте. Это подтверждается различиями в клинической картине заболевания, течении и прогнозе у детей и взрослых, что, возможно, обусловлено различными генетическими мутациями. Полученные научные данные о присутствии неодинаковых мутаций при различных кожных и системных формах мастоцитоза могут служить основанием для дальнейшего изучения генетических основ мастоцитоза, что необходимо не только для расширения знаний о патогенезе этого заболевания, но и для создания патогенетически обоснованных методов его терапии. Так, исследователями выявлено, что больные мастоцитозом, имеющие мутацию c-kit D816V, резистентны к препарату Иматиниб [63]. В настоящее время уже проводятся клинические исследования генно-инженерных препаратов Дазатиниб (dasatinib) и Нилотиниб (nilotinib), активных против c-kit D816V-позитивных клеток [15, 63]. Расширение знаний о генотипе больных мастоцитозом может быть полезно для разработки новых эффективных для лечения этого заболевания препаратов генно-инженерной биологической терапии.

\section{Литература}

1. Akin C., Valent P., Diagnostic criteria and classification of mastocytosis in 2014. Immunol Allergy Clin North Am 2014; 34: 207-218.

2. Azana J. M. Urticaria pigmentosa: a review of 67 paediatric cases. Ped. Dermatol 1994; (11): 102-106.
3. Fernandez A. T., Campoamor L. N., Mora L. E. et al. Diagnostico, tratamiento y clasification de la mastocitosis pediatrica. Estudio de 172 casos. Actas. Dermosifiliogr 1998; (89): 461—476.

4. Kettelhut B. V., Metacalfe D. Pediatric mastocytosis. J Invest Dermatol 1991; 96 (Suppl.): 15-18.
5. Castells M. Mastocytosis: classification, diagnosis and clinical presentation Allergy. Asthma. 2004; (25): 33—36.

6. Lanternier F., Cohen-Akenine A., Palmerini F., Feger F., Yang Y., Zermati Y., et al. Phenotypic and genotypic characteristics of mastocytosis according to the age of onset. PLoS One. 2008; (3): $19-26$. 
7. Tereshchenko V. N. Generalizovannaya uzlovato-infiltrativnaya forma mastotsitoza. Rossiyskiy zhurnal kozhnykh i venericheskikh bolezney. 2005; (3): 29-31. [Терещенко В. Н. Генерализованная узловато-инфильтративная форма мастоцитоза. Российский журнал кожных и венерических болезней. 2005; (3): 29-31.]

8. Sagher F., Even-Paz A. Mastosytosis and the mast cell. Chicago; 1967; Fine J. Mastosytosis. Int J Dermatol 1980; 19: 117-123.

9. Hartmann K., Henz B. M. Mastosytosis: resent advances in defining the disease. Br J Dermatol 2001; 144: 682-695.

10. Torrelo A., Alvarez-Twose I., Escribano L. Childhood mastocytosis. Curr Opin Pediatr 2012; (24/4): 480—486.

11. Brockow K., Metcalfe D. D. Mastocytosis, Clinical immunology - principles and practice. Mosby International Ltd, London, Edinburgh, New York 2001; 11: 23-28.

12. Pardanani A., Kimlinger T., Reeder T. Bone marrow mast cell immunophenotyping in adults with must cells diseases: a prospective study of 33 patients. Leuk Res 2004; (28): 777—783.

13. Leonardi S., Vitaliti G., Pratico A. D., La Rosa M. Telangiectasia macularis eruptive perstans (TMEP) in childhood: a case report and literature review. Allergol Immunopathol (Madr). 2012; 40: 321-323.

14. Fried A. J., Akin C. Primary mast cell disorders in children. Curr Allergy Asthma Rep 2013; (13/6): 693-701.

15. Dirk Van Gysel et al., Mastocytosis: a comprehensive insight. Giornale italiano di dermatologia e venereologia: organo ufficiale, Societa italiana di dermatologia e sifilografia 2016; (08): 1 -3.

16. Silva I. Mastocytosis: a rare case of anaphylaxis in pediatric age and literature review. Allergo Immunopathol 2008; 36: 154-163.

17. Proshutinskaya D. V., Makovetskaya 0. S. Klinicheskaya kharakteristika kozhnykh form mastotsitoza u detey. XVI Vserossiyskiy syezd dermatovenerologov i kosmetologov. M, 2016; 31-32. [Прошутинская Д. В., Маковецкая 0. С. Клиническая характеристика кожных форм мастоцитоза у детей. XVI Всероссийский съезд дерматовенерологов и косметологов. М, 2016; 31-32.]

18. Shiloh Malawsky Y., Confino Y., Yosipovitz A., Nassan D., Augarten A. Mastocytosis: The paediatric emergency physician's perspective. Pediatr. Emerg. Care. 2003; (19): 17—23.

19. Lim K. N, Tefferi A., Lasho T. L. et al. Systemic mastocytosis in 342 consecutive adults: survival studies and prognostic factors. Blood 2009; 113: $27-36$.
20. Fernandez A. T., Campoamor L. N., Mora L. E. et al. Diagnostico, tratamiento y clasification de la mastocitosis pediatrica. Estudio de 172 casos. Actas. Dermosifiliogr 1998; (89): 461—476.

21. Jordan R., Fritsche Polanz, W. R. Sperr et al. A case of "smouldering» mastocytosis with high mast cell burden, monoclonal myeloid cells, and CKIT mutation Asp816Val. J Leuk. Res 2001; (25): 627-634.

22. Vigovskaya Ya.I., Serafin N.Ya.. Lozinskaya M.R. i dr. Sluchay mastotsitarnoy leykemii. Ukrainskiy zhurnal gematologii i transfuziologii. 2006; (6): 32-36. [Виговская Я.И., Серафин Н. Я., Лозинская М.Р. и др. Случай мастоцитарной лейкемии. Украинский журнал гематологии и трансфузиологии. 2006; (6): 32-36.]

23. Yarilin A.A. Osnovy immunologii: uchebnik. M: Meditsina. 1999; (1): 608-609. [Ярилин А.А. Основы иммунологии: учебник. М: Медицина, 1999; (1): 608—609.]

24. Feger F., Ribadeau Dumas A., Leriche $L$ et al. Kit and c-kit mutations in mastocytosis: a short overview with special reference to novel molecular and diagnostic concepts. Int Arch Allergy Immunol 2002; 127: 110_114.

25. Escribano L. Prognosis in sdult indolent sysctemic mastocytosis: a lonfterm study of the Spanish Network on Mastocytosis in a series of 145 patients. Allergy Clin Immunol 2009; (3): 514-521.

26. Wolff K. Clinical and pathological aspects of cutaneous mastocytosis. 2001; 25: 603-625.

27. Kitamura Y., Kasugai T., Arisono N. et al. Development of mast cells and basophils: processes and regulation mechanisms. Am J Med Sci 1993; 306: 185-191.

28. Welker P., Grabbe J., Gibbs B. et al. Nerve growth factor-beta induces mast-cell marker expression during in vitro culture of human umbilical cord blood cells. Immunology 2000; 99: 418-426.

29. Hartman K., Henz B. Classification of cutaneous mastocytosis: a modified consensus proposal. Leuk Res 2002; 26: 485-486.

30. Orfao A., Garsia-Montero A. C., Sanchez L. et al. Recent advances in the understanding of mastocytosis: the role of KIT mutations. Br J Haematol 2007; 138: 12-30.

31. Furitsu T., Tsujimura T., Tono T., Ikeda H., Kitayama H., Koshimizu Uet al. Identification of mutations in the coding sequence of the protooncogene c-kit in a human mast cell leukemia cell line causing ligand-independent activation of ckit product. J Clin Invest 1993; 92: 1736_-1744.

32. Longley B. J., Reguera M. J., Ma Y. Classes of C-KIT activating mutations: proposed mechanisms of action and implications for disease classification and therapy. Leuk Res 2001; 25 : $571-576$.
33. Golkar L., Bernhard J. D. Biomedical reference collection: comprehensive seminar for mastocytosis. Lancet 1997; 349 (9062): 1379—1385.

34. Horny H. P., Sotlar K., Valent P., Hartmann K. Mastocytosis. Dtsch Arztebl Int 2008; 105 : 686-692.

35. Soter N. A. Mastocytosis and the skin. Hematol Oncol Clin North Am 2000; 14: 537—555.

36. Ma D., Stence A.A., Bossler A.B., Hackman J.R., Bellizzi A.M. Identification of KIT activating mutations in paediatric solitary mastocytoma. Histopathology 2014; (64): 218-25.

37. Bodemer C., Hermine O., Palmerini F. et al. Pediatric mastocytosis is a clonal disease associated with D816 and other activating C-KIT mutations. J Invest Dermatol 2010; (130): 804-815.

38. Ustun C., Corless C. L., Savage N. et al. Chemotherapy and dasatinib induce longterm hematologic and molecular remission in systemic mastocytosis with acute myeloid leukemia with KIT D816V. Leuk Res 2009; (33): 735—741.

39. Ken Hong L., Tefferi A. Systemic mastocytosis in 342 consecutive adults: survival studies and prognostic factors. Blood 2009; (113): 5727—5736.

40. Worobec A. Treatment of systemic mast cell disorders. Hematol. Oncol. Clin. North Am. 2000; (14): 659—687.

41. Ben-Amitai D., Metzker A., Cohen H. A. Pediatric cutaneous mastocytosis: a review of 180 patients. Isr Med Assooc J 2005; 7: 320—322.

42. Carter M. C., Clayton S. T., Komarow H. D., assessment of clinical findings, tryptase levels and bone marrow histopathology in the management of pediatric mastocytosis. J Allergy Clin Immunol 2015; 04: 20—24.

43. Zakhartseva L. M., Shatrova K. M.. Krachok I. A., Dyatel M. V., Kadnikova T. V., Filonenko E. S., Titorenko I. B., Glavinskiy E. A. Sistemnyy mastotsitoz $s$ preimushchestvennym porazheniyem kostnoy i limfaticheskoy sistemy (Obzor literatury i sluchay iz praktiki). Onkologiya. 2015; (17): 236-242. [Захарцева Л. М., Шатрова К. М., Крачок И.А., Дятел М.В., Кадникова Т.В., Филоненко Е. С., Титоренко И. Б., Главинский Е.А. Системный мастоцитоз с преимущественным поражением костной и лимфатической системы (Обзор литературы и случай из практики). Онкология. 2015; (17): 236-242.]

44. Tefferi A., Vardiman J.W. Classification and diagnosis of myeloproliferative neoplasms: the 2008 World Health Organization criteria and point-ofcare diagnostic algorithms. Leukemia 2008; 22:14-22.

45. Hartmann K. et al., Cutaneous manifestation in patients with mastocytosis.: Consensus report of the European Competence Network on Mastocytosis. J Allergy Clin Immynol 2016; 137: 35—45. 
46. Wiechers T., Rabenhorst A., Schick T., Preussner L. M., Forster A., valent P. et al. Large maculopapular cutaneous lesions are associated with favorable outcome in childhood-onset mastocytosis. J Allergy Clin Immunol 2015; 05: 30—34.

47. Lange M., Nedoszytko B., Gorska A., Zawrocki $A$. et al. Mastocytosis in children and adults: clinical disease heterogeneity. Arch Med Sci 2012; 8: 533—541.

48. Teodosio C., and prognostic subtypes of systemic mastocytosis display distinct immunophenotypes. J Allergy Clin Immunol 2010; 125: 719—726.

49. Chan Ec, Bai Y., Kirshenbaum A. S., Fisher E. R. et al. Mastocytosis associated with a rare germline KIT K509I mutation displays a welldifferentiated mast cell phenotype. J Allergy Clin Immunol 2014; 134: 178-187.

50. Longley B. J., Tyrrell L., Lu S.Z., Ma Y.S., Langley K., Ding T.G., Duffy T., Jacobs P., Tang L. H., Modlin I.: Somatic c-KIT activating mutation in urticaria pigmentosa and aggressive mastocytosis: establishment of clonality in a human mast cell neoplasm. Nat Genet 1996; 12: $312-314$.

51. Longley B.J., Metcalfe D.D., Tharp M., Wang X., Tyrrell L., Lu S. Z., Heitjan D., Ma Y.: Activating and dominant inactivating c-KIT catalytic domain mutations in distinct clinical forms of human mastocytosis. Proc Natl Acad Sci USA 1999; 96: 1609—1614.
52. Sotlar K., Marafioti T., Griesser H., Theil J., Aepinus C., Jaussi R., Stein H., Valent P., Horny H. P.: Detection of c-kit mutation Asp 816 to Val in microdissected bone marrow infiltrates in a case of systemic mastocytosis associated with chronic myelomonocytic leukaemia. Mol Pathol 2000; 53: 188-193.

53. Hirokatsu Yanagihori, Noritaka Oyama, Koichiro Nakamura, and Fumio Kaneko. c-kit Mutations in Patients with Childhood-Onset Mastocytosis and Genotype-Phenotype Correlation. J Molecular Diagnostics 2005; 7: 241-244.

54. Sotlar Karl, Luis Escribano, Olfert Landt, Stefanie Mohrle, Sonia Herrero, Antonio Torrelo, Ulrich Lass, Hans-Peter Horny, and Burkhard Bultmann. One-Step Detection of c-kit Point Mutations Using Peptide Nucleic Acid-Mediated Polymerase Chain Reaction Clamping and Hybridization Probes.Am J Pathol 2003; 162 : 737-746.

55. Bradding P. Human Mast Cell Cytokines. CEA 1996; (26/1): 13—19.

56. Valent P., Horny H. P., Escribano L., Longley B. J., Li C. Y., Schwartz L. B., et al. Diagnostic criteria and classification of mastocytosis: a consensus proposal. Leuk Res 2001; 25: $603-625$.

57. Soter N. A. Mastocytosis and the skin. Hematol. Oncol. Clin. North Am 2000; (14): 557—564.
58. Heide R., de Waard-van der Spek F. B., den Hollander J. C., Tank B., Oranje A. P. Efficacy of $25 \%$ diluted fluticasone propionate $0,05 \%$ cream as wet-wrap treatment in cutaneous mastocytosis. Dermatology 2007; 214: 333-335.

59. Castells M. Mastocytosis: classification, diagnosis and clinical presentation. Allergy 2004; (25): 33-36.

60. Granerus G., Roupe G., Swanbeck G. Decreased urinary histamine metabolite after successful PUVA treatment of urticaria pigmentosa. J Invest Dermatol 1981; 76: 1—3.

61. Sokol K.C., Ghazi A., Kelly B.C., Grant J.A. Omalizumab as a desensitizing agent and treatment in mastocytosis: a review of the literature and case report. The journal of allergy and clinical immunology in practice, 2014; 2 : 266-270.

62. Lieberoth S., Thomsen S. F. Cutaneous and gastrointestinal symptoms in two patients with systemic mastocytosis: a review of the literature and case report. J allergy clini immunol practice 2015; 90: 35-41.

63. Hoffmann K. M, Moser A., Lohse P., Winkler A., Binder B., Sovinz P. et al. Successful treatment of progressive cutaneous mastocytosis with imatinib in 2-year-oid boy carrying a somatic KIT mutation. Blood 2008; 112: 1655-1657.

об авторах:

Д. В. Прошутинская — ведущий научный сотрудник отделения детской дерматологии ФГБУ «ГНЦДК» Минздрава России, Москва

0. С. Маковецкая — врач консультативно-диагностического центра ФГБУ «ГНЦДК» Минздрава России, Москва

\section{Конфликт интересов}

Авторы заявляют об отсутствии потенциального конфрликта интересов, требующего раскрытия в данной статье 